\title{
Solidification microstructure selection of the peritectic Nd-Fe-B alloys
}

\author{
ZHONG Hong, LI ShuangMing ${ }^{\dagger}$, LÜ HaiYan, LIU Lin, ZOU GuangRong \& FU HengZhi \\ State Key Laboratory of Solidification Processing, Northwestern Polytechnical University, Xi'an 710072, \\ China \\ Bridgman directional solidification and laser remelting experiments were carried \\ out on $\mathrm{Nd}_{11.76} \mathrm{Fe}_{82.36} \mathrm{~B}_{5.88}$ and $\mathrm{Nd}_{13.5} \mathrm{Fe}_{79.75} \mathrm{~B}_{6.75}$ alloys. Microstructure evolutions along \\ with solidification parameters (temperature gradient $G$, growth velocity $V$ and initial \\ alloy composition $C_{0}$ ) were investigated. A solidification microstructure selection \\ map was established, based on the consideration of solidification characteristics of \\ peritectic $T_{1}$ phase. In Bridgman directional solidification experiments, with the \\ increasing growth velocities, the morphology of $T_{1}$ phase changed from plane front \\ or faceted plane front to dendrites. In laser remelting experiments, a transition from \\ primary $\gamma$-Fe dendrites to $T_{1}$ dendrites was found. Theoretical predictions are in \\ good agreement with experimental results.
}

peritectic alloy, directional solidification, microstructure selection

Peritectic alloy has been widely used in industry, and its solidification behavior has attracted increasing attention in recent years. According to the compositional range of a peritectic phase, the peritectic alloys can be divided into two type ${ }^{[1]}$ : Type $\mathrm{A}$, the peritectic phase has a certain range of solubility, such as $\mathrm{Cu}-\mathrm{Zn}, \mathrm{Fe}-\mathrm{C}$ and $\mathrm{Fe}-\mathrm{Ni}$; Type $\mathrm{B}$, the solubility range of the peritectic phase is very small, such as $\mathrm{Cu}-\mathrm{Sn}$ and $\mathrm{YBCO}$. Magnetic material Nd-Fe-B belongs to Type B system. The superiority of $\mathrm{Nd}-\mathrm{Fe}-\mathrm{B}$ magnets mainly originates from the peritectic $\mathrm{T}_{1}$ phase $-\mathrm{Nd}_{2} \mathrm{Fe}_{14} \mathrm{~B}$ intermetallic compound, which has a large saturation magnetization and a high anisotropy field ${ }^{[2]}$. In order to make full use of the good intrinsic properties, the volume fraction of $\mathrm{Nd}_{2} \mathrm{Fe}_{14} \mathrm{~B}$ in magnets should be maximized, and their (001) crystalline axes should be well aligned ${ }^{[3]}$. In addition to the hard magnetic $\mathrm{T}_{1}$ phase, other nonmagnetic and soft magnetic phases also take place in the solidification of Nd-Fe-B alloys, depending on the composition and processing conditions. Therefore, better understanding and control of the solidification process must be obtained to optimize the hysteretic magnetic properties of the Nd-Fe-B alloys.

Directional solidification is an available technique to study the microstructure selection of alloys,

Received February 11, 2007; accepted April 29, 2007

doi: 10.1007/s11433-007-0041-y

†Corresponding author (email: 1sm@nwpu.edu.cn)

Supported by the National Natural Science Foundation of China (Grant No. 50395100) 
due to its facility of solidification parameter control. Recently, several authors ${ }^{[4-10]}$ have focused on directional solidification of Type A peritectic alloys. The microstructure selection of these alloys has been successfully treated by comparing the steady state interface temperatures of competing phases. However, little attention has been devoted to Type B peritectic alloys and the solidification behavior of such alloys has not been well understood.

The aim of this study is to establish a solidification phase and microstructure selection map for Nd-Fe-B alloys at a wide range of growth velocities. Bridgman directional solidification and laser remelting experiments were carried out to evaluate the effects of composition, temperature gradient and growth velocity on the phase and microstructure selection. Solidification microstructure selection maps were presented and compared with experimental results.

\section{Experiment}

To investigate the solidification microstructure selection of Nd-Fe-B alloys, two types of directional solidification experiments were performed. Bridgman experiments were done at low velocities; laser remelting experiments were carried out at higher velocities.

\subsection{Experimental procedure}

Bridgman directional solidification experiments were undertaken for Nd-Fe-B alloys with different chemical compositions $\left(\mathrm{Nd}_{11.76} \mathrm{Fe}_{82.36} \mathrm{~B}_{5.88}\right.$ and $\mathrm{Nd}_{13.5} \mathrm{Fe}_{79.75} \mathrm{~B}_{6.75}$, at\%). The as-cast rod was machined to be $4 \mathrm{~mm}$ in diameter and $100 \mathrm{~mm}$ in length or $7 \mathrm{~mm}$ in diameter and $115 \mathrm{~mm}$ in length. The sample was put in an alumina crucible and solidified in a high thermal gradient Bridgman furnace ${ }^{[11]}$. The growth velocity changed from $1-300 \mu \mathrm{m} / \mathrm{s}$. The sample was heated to $1400^{\circ} \mathrm{C}$ and then moved through the furnace at a constant speed. After the sample reached $50 \mathrm{~mm}$, the crucible was dropped into the cooling bath, in order to quench the solid/liquid interface. The mean thermal gradient, measured at different $\mathrm{S} / \mathrm{L}$ interfaces with an inserted PtRh30-PtRh6 thermocouple, is shown in Figure 1. The thermal gradient decreased as the withdrawal velocity increased.

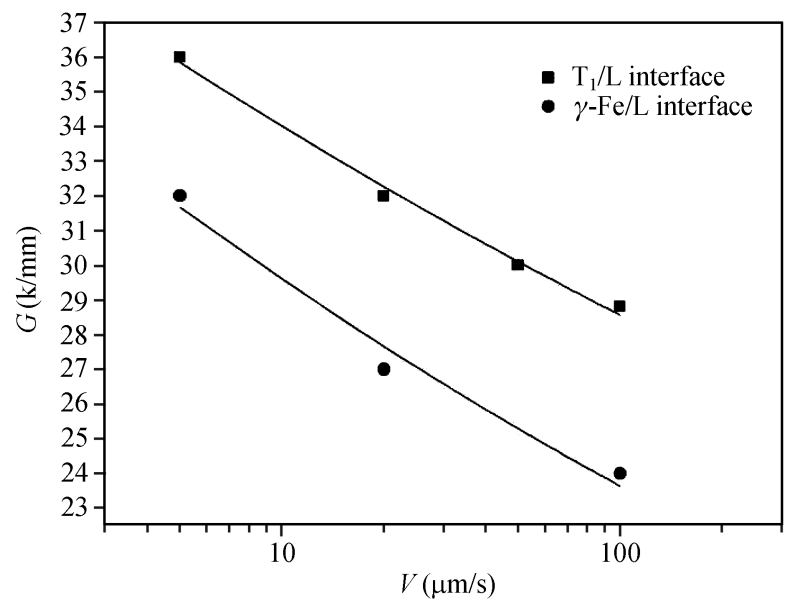

Figure 1 Dependence of temperature gradient $G$ on withdrawal velocity $V$. 
Laser surface remelting experiments were performed on $\mathrm{Nd}_{13.5} \mathrm{Fe}_{79.75} \mathrm{~B}_{6.75}$ (at\%) hyperperitectic alloys. The experiments were carried out using a $5 \mathrm{~kW}$ continuous wave $\mathrm{CO}_{2}$ laser (Rofin-Sinar $850)^{[12]}$. The laser beam was focused on a spot with the diameter of $0.5 \mathrm{~mm}$, and a power density of $5090 \mathrm{~W} \cdot \mathrm{mm}^{-2}$ with the scanning velocities between 5 and $20 \mathrm{~mm} / \mathrm{s}$ was obtained. The molten pool was protected by blowing a continuous flow of helium $\left(10 \mathrm{~min}^{-1}\right)$ on the solidifying surface to prevent heavy oxidation during the laser treatment. Local growth rate $V_{\mathrm{S}}$ could be related to the scanning velocity $V_{\mathrm{b}}$, via the expression $V_{\mathrm{S}}=V_{\mathrm{b}} \cos \theta^{[12]}$, where $\theta$ is the acute angle between $V_{\mathrm{b}}$ and $V_{\mathrm{S}}$.

All specimens were cut along the transverse and longitudinal direction, respectively. Then, the samples were polished and etched with $3 \%$ Nital to reveal the as-solidified microstructures . The microstructures were analyzed by a Leica DM4000M optical microscope.

\subsection{Experimental results}

Solidification microstructures consisting of primary $\gamma$-Fe ( $\alpha$-Fe at room temperature) dendrites, peritectic $T_{1}$ phase and black Nd-rich phase were obtained at growth rates ranging from 1 to 300 $\mu \mathrm{m} / \mathrm{s}$. Figure 2 shows the typical microstructures of Bridgman directional solidification samples. The $\mathrm{S} / \mathrm{L}$ interface morphologies of $\mathrm{T}_{1}$ phase at different velocities are shown in Figure 3, which changed from faceted/plane front to faceted dendrites with increasing growth rates. At withdrawal velocities between 1 and $300 \mu \mathrm{m} / \mathrm{s}$, the $\mathrm{S} / \mathrm{L}$ interface of $\gamma$-Fe kept dendrites (Figure 4) and always led the $\mathrm{S} / \mathrm{L}$ interface of $\mathrm{T}_{1}$ phase.
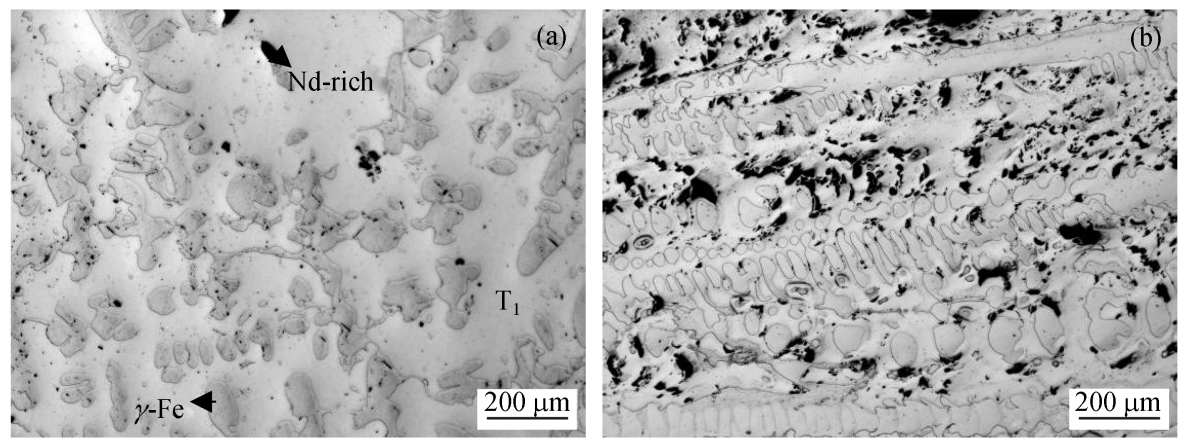

Figure 2 Optical micrograph of directionally solidified $\mathrm{Nd}_{13.5} \mathrm{Fe}_{79.75} \mathrm{~B}_{6.75}$ alloy, $V=2 \mu \mathrm{m} / \mathrm{s}$. (a) Transverse section; (b) longitudinal section.

In laser surface remelting experiments of $\mathrm{Nd}_{13.5} \mathrm{Fe}_{79.75} \mathrm{~B}_{6.75}$ alloy, at growth velocity of $4.4 \mathrm{~mm} / \mathrm{s}$, the microstructures consisted of primary $\gamma$-Fe dendrites, peritectic $\mathrm{T}_{1}$ dendrites and Nd-rich phase. At growth velocity of $5.0 \mathrm{~mm} / \mathrm{s}$, only primary $\mathrm{T}_{1}$ faceted dendrites and $\mathrm{Nd}$-rich phase were found, as shown in Figure 5.

\section{Interface responses of $\gamma$-Fe and $T_{1}$ phases}

The interface temperatures which, for a given alloy, are a function of composition, growth velocity and temperature gradient are called Interface Response Functions ${ }^{[1]}$. The highest interface temperature criterion is a strong indication of the structure to be formed ${ }^{[13]}$. 

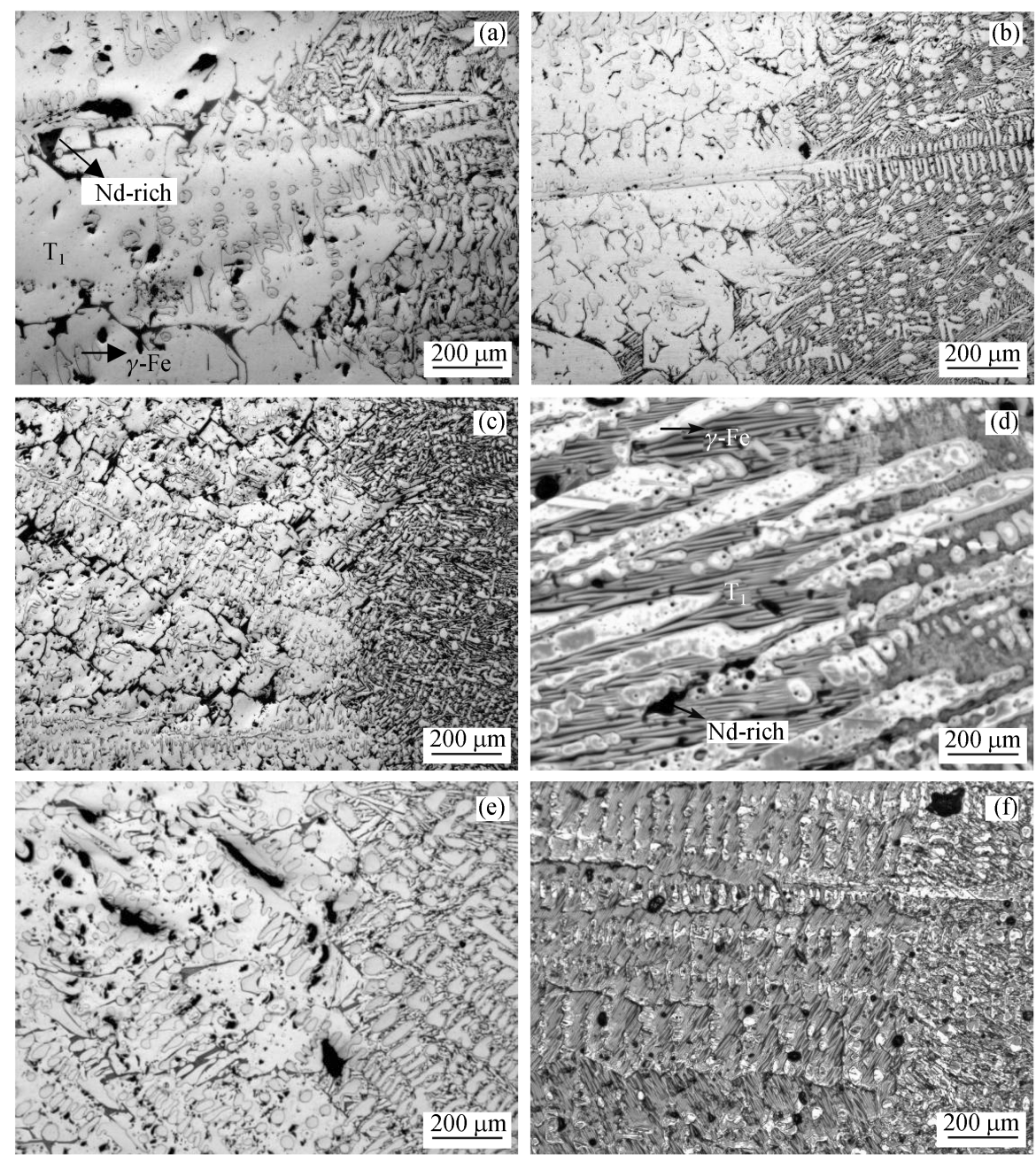

Figure 3 Dependence of $\mathrm{T}_{1} / \mathrm{L}$ interface morphology on withdrawal velocity. (a) $\mathrm{Nd}_{13.5} \mathrm{Fe}_{79.75} \mathrm{~B}_{6.75}, V=5 \mu \mathrm{m} / \mathrm{s}$; (b) $\mathrm{Nd}_{13.5} \mathrm{Fe}_{79.75} \mathrm{~B}_{6.75}, V=20 \mu \mathrm{m} / \mathrm{s}$; (c) $\mathrm{Nd}_{13.5} \mathrm{Fe}_{79.75} \mathrm{~B}_{6.75}, V=50 \mu \mathrm{m} / \mathrm{s}$; (d) $\mathrm{Nd}_{11.76} \mathrm{Fe}_{82.36} \mathrm{~B}_{5.88}, V=1 \mu \mathrm{m} / \mathrm{s}$; (e) $\mathrm{Nd}_{11.76} \mathrm{Fe}_{82.36} \mathrm{~B}_{5.88}, V=5$ $\mu \mathrm{m} / \mathrm{s}$; (f) $\mathrm{Nd}_{11.76} \mathrm{Fe}_{82.36} \mathrm{~B}_{5.88}, V=20 \mu \mathrm{m} / \mathrm{s}$. (d), (f) Microstructures with Bitter domain observation; (a), (e) faceted plane front; (d) plane front; (b), (c), (f) dendritic interface.
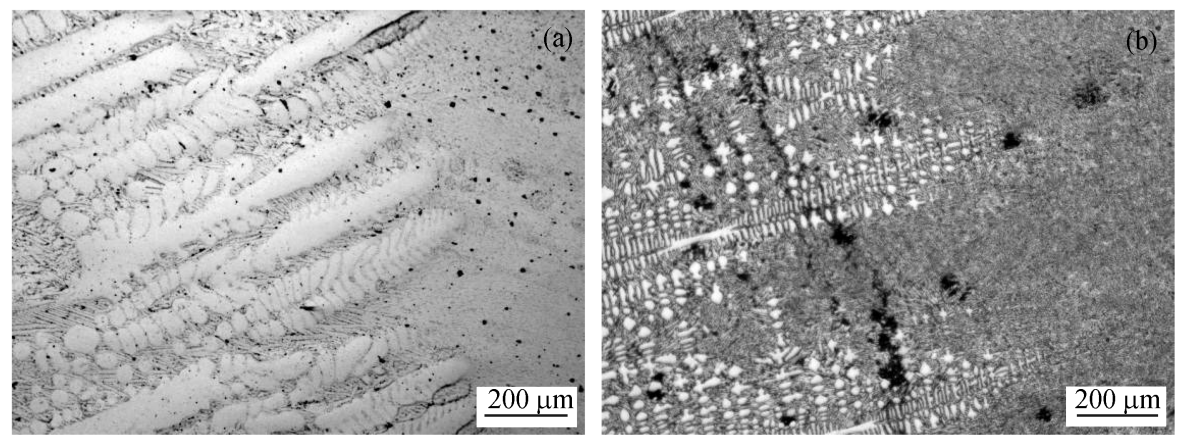

Figure 4 Microstructures observed at the solid/liquid interface of $\gamma$-Fe in directionally solidified $\mathrm{Nd}_{11.76} \mathrm{Fe}_{82.36} \mathrm{~B}_{5.88}$ alloy. (a) $V=$ $1 \mu \mathrm{m} / \mathrm{s}$; (b) $V=50 \mu \mathrm{m} / \mathrm{s}$. 


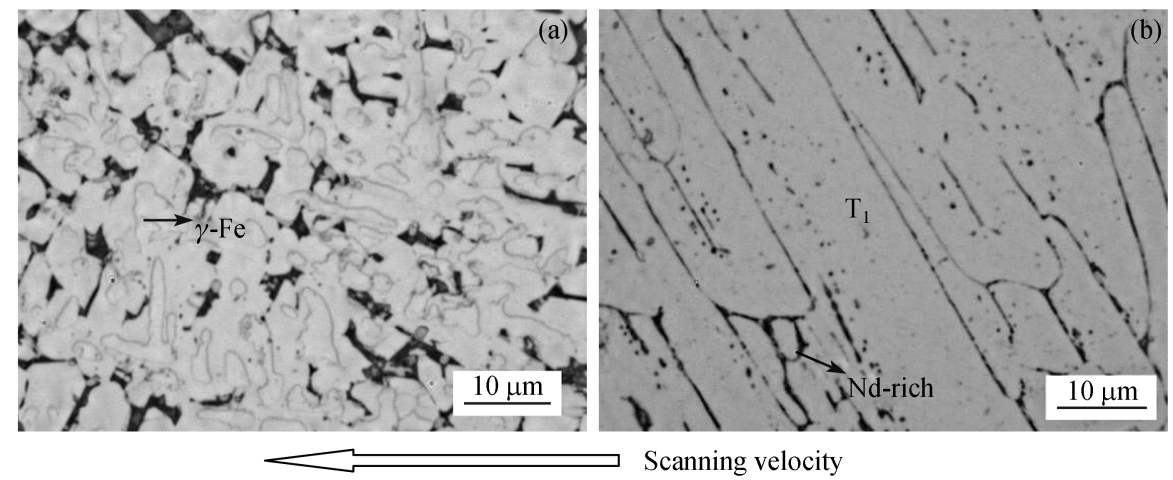

Figure 5 Typical microstructure from the longitudinal section of $\mathrm{Nd}_{13.5} \mathrm{Fe}_{79.75} \mathrm{~B}_{6.7}$ alloy under different solidification velocities. (a) $V_{\mathrm{b}}=5 \mathrm{~mm} / \mathrm{s}\left(V_{\mathrm{S}}=4.4 \mathrm{~mm} / \mathrm{s}\right) ;(\mathrm{b}) V_{\mathrm{b}}=10 \mathrm{~mm} / \mathrm{s}\left(V_{\mathrm{S}}=5 \mathrm{~mm} / \mathrm{s}\right)$.

As indicated in Figure 6, Nd-Fe-B phase diagram shows the following characteristics: (1) The $\mathrm{Nd}$ content in $\gamma$-Fe is very small; (2) the peritectic $\mathrm{T}_{1}$ phase is an intermetallic compound which has a constant $\mathrm{Nd}$ content. In such a case, the interface responses (Figure 7) of $\gamma$-Fe and $\mathrm{T}_{1}$ phases are calculated. And the velocity for a transition from one phase/morphology to another is presented below.

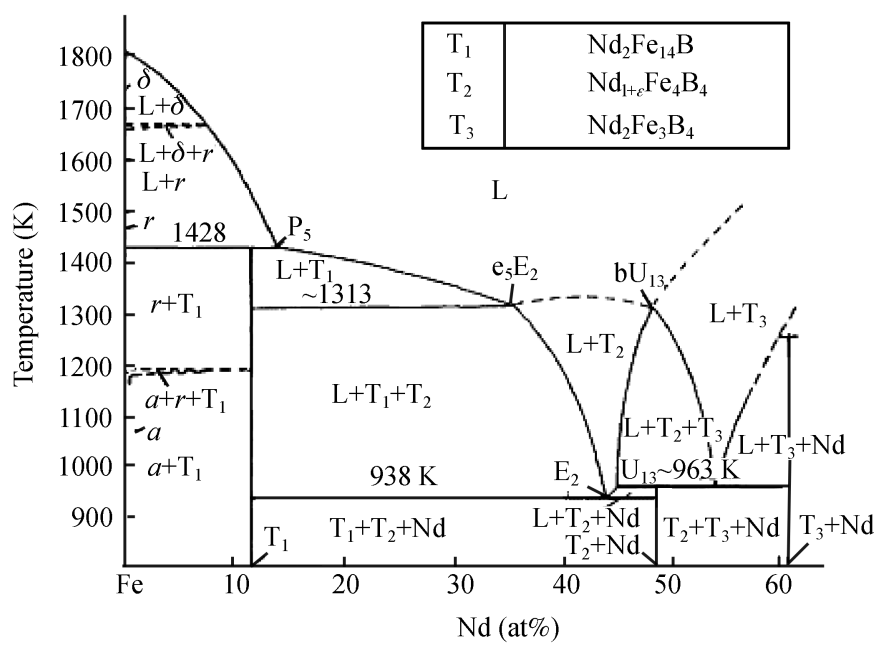

Figure 6 A vertical section of $\mathrm{Nd}-\mathrm{Fe}-\mathrm{B}$ phase diagram of $\mathrm{Nd}: \mathrm{B}=2: 1^{[14]}$.
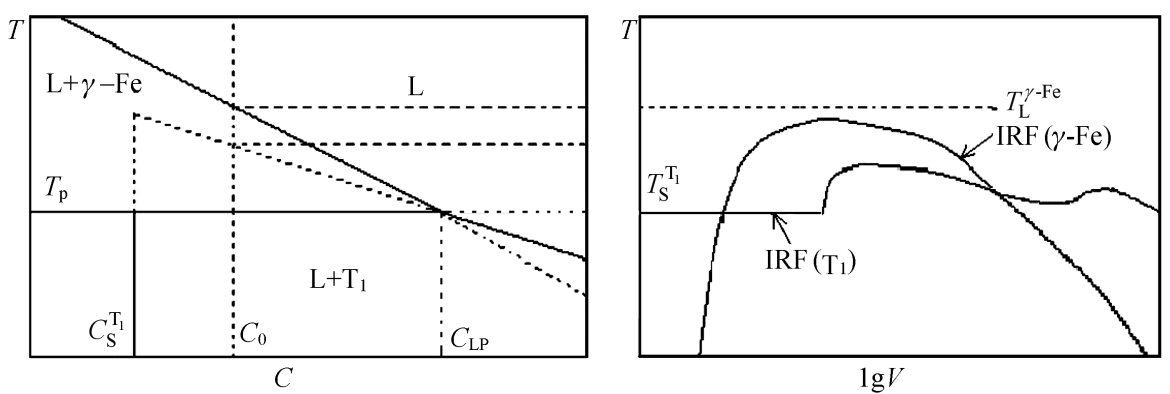

Figure 7 Schematic phase diagram for Nd-Fe-B peritectic alloy and the interface temperature changing with the growth rate. 


\subsection{Plane front growth at low velocities}

The growth temperature of a single phase plane front is given by ${ }^{[13]}$

$$
T(P)=T_{\mathrm{S}}-\Delta T_{\mathrm{k}},
$$

where $T_{\mathrm{S}}$ is the equilibrium solidus temperature; $\Delta T_{\mathrm{k}}=V / \mu$ is the attachment kinetic undercooling $\left(\mu\right.$ is the linear kinetic coefficient ${ }^{[15]}$, and its value is in the order of $0.001-0.01$ $\mathrm{m} \cdot \mathrm{s}^{-1} \cdot \mathrm{K}^{-1}$ for an intermetallic alloy). Here $T(P)$ is assumed to be $T_{\mathrm{S}}$ due to a negligible attachment kinetic undercooling that is typically less than $0.1 \mathrm{~K}$.

Plane front is morphologically stable at very low velocities $\left(V \leqslant V_{\mathrm{C}}\right.$, constitutional undercooling ${ }^{[16]}$ ) in directional solidification:

$$
V_{\mathrm{C}}=\frac{G D}{m\left(C_{0}-C_{0} / k_{0}\right)},
$$

where $D$ is the diffusion coefficient in liquid, $m$ is the liquidus slope, and $k_{0}$ is the equilibrium distribution coefficient.

(i) Plane front growth of $\gamma$-Fe at low velocities. In the $\mathrm{Nd}-\mathrm{Fe}-\mathrm{B}$ phase diagram (Figure 6), $C_{\mathrm{S}}^{\gamma-\mathrm{Fe}}$ is close to zero, so that the solidification behavior of $\gamma$-Fe would be characteristic as $k_{0}^{\gamma \text {-Fe }}=0$ case. Eq. (2) then predicts that $V_{\mathrm{C}}^{\gamma \text {-Fe }}$ will approach zero. Therefore a plane front growth of $\gamma$-Fe would be very difficult to form.

(ii) Plane front growth of $\mathrm{T}_{1}$ phase at low velocities. During solidification of a common alloy $\left(k_{0}<1\right)$, the fully developed diffusion boundary layer was established gradually during a transient period. For $T_{1}$ phase, such a transient period would not exist. At low velocities, $T_{1}$ plane front phase has a fixed composition and it does not change with the initial alloy composition. The solute concentrations in the solid and liquid at the interface are $C_{\mathrm{S}}^{\mathrm{T}_{1}}$ and $C_{\mathrm{LP}}$, respectively, which are independent of the original composition and keep unchanged in directional solidification, so the steady state boundary layer of $\mathrm{T}_{1}$ phase is different from that of a common alloy, as shown in Figure 8.

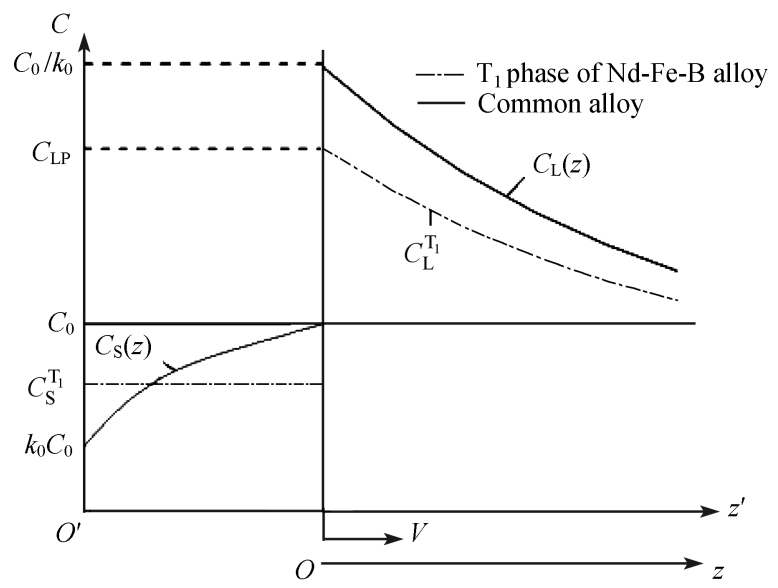

Figure 8 Steady state distribution of solute in the liquid ahead of the freezing solid-liquid interface.

The liquid solute concentration distribution ahead of a plane solid/liquid interface under steady-state conditions at low velocities could be expressed in an exponential form ${ }^{[16]}$. For $\mathrm{T}_{1}$ phase, 
it could be expressed as

$$
C_{\mathrm{L}}(z)=C_{0}+\left(C_{\mathrm{LP}}-C_{0}\right) \exp \left(-\frac{V}{D} z\right),
$$

where $C_{\mathrm{LP}}$ is the liquid concentration at the peritectic temperature $T_{\mathrm{P}}$ (Figure 7).

Therefore, the constitutionally undercooled would not occur when eq. (4) is satisfied:

$$
V \leqslant V_{\mathrm{C}}^{\mathrm{T}_{1}}=\frac{G D}{m\left(C_{0}-C_{\mathrm{LP}}\right)} .
$$

Now compare eq. (4) with eq. (2). The $m\left(C_{0}-C_{0} / k_{0}\right)$ term in eq. (2) indicates the crystallization temperature interval for an alloy of composition $C_{0}$; the $m\left(C_{0}-C_{\mathrm{LP}}\right)$ term in eq. (4) denotes the temperature interval between the extended liquidus temperature of $T_{1}$ phase and the peritectic temperature for an alloy of composition $C_{0}$.

\subsection{Competition growth between $\gamma$-Fe and $\mathrm{T}_{1}$ dendrites}

Umeda et al. ${ }^{[1]}$ have studied the phase selection of Nd-Fe-B alloys at high velocities. Critical velocities for transition from $\gamma$-Fe to $\mathrm{T}_{1}$ dendrites have been calculated in their paper. But the solidification characteristic of $\mathrm{T}_{1}$ phase was not considered.

During directional solidification, the growth temperature of a dendrite is often written as ${ }^{[16]}$

$$
T_{\mathrm{d}}=T_{1}-\Delta T,
$$

where $T_{1}$ is the liquidus temperature.

At the same time, tip undercooling for columnar dendrites can be expressed by

$$
\Delta T=\Delta T_{\mathrm{C}}+\Delta T_{\mathrm{r}},
$$

where $\Delta T_{\mathrm{r}}$ is the curvature undercooling, the value of which is typically in the order of $0.01-0.1 \mathrm{~K}$ so that it could be neglected. At small Péclet number $(P=V R / 2 D)$, expression for the solute undercooling $\Delta T_{\mathrm{C}}$ is

$$
\Delta T_{\mathrm{C}}=m\left(C_{0}-C_{1}^{*}\right) \cong-m C_{0} \Omega p,
$$

where $p=1-k_{0} ; \Omega$ is the solutal supersaturation,

$$
\Omega=\frac{C_{\mathrm{LP}}-C_{0}}{C_{\mathrm{LP}}-C_{\mathrm{S}}^{\mathrm{T}_{1}}}=\frac{C_{\mathrm{LP}}-C_{0}}{C_{\mathrm{LP}} p} .
$$

In this paper, $k_{0}^{\mathrm{T}_{1}}$ refers to the distribution coefficient at interface,

$$
k_{0}^{\mathrm{T}_{1}}=k_{\mathrm{i}}^{\mathrm{T}_{1}}=C_{\mathrm{S}}^{\mathrm{T}_{1}} / C_{\mathrm{LP}} .
$$

Note that, for a common alloy, the $-m C_{0} p$ term in eq. (7) is often substituted by $\Delta T_{0} k_{0}{ }^{[16]}$; but for $\mathrm{T}_{1}$ phase of Nd-Fe-B alloy, $-m C_{0} p$ is not the same as $\Delta T_{0} k_{0}$.

For the supersaturation $\Omega \sim 2 P$ (when $P$ is small) ${ }^{[1]}$, eq. (7) becomes

$$
\Delta T_{\mathrm{C}} \cong-m C_{0} p R V / D \text {. }
$$

Here $\Delta T_{\mathrm{C}}$ is the solute undercooling with $G=0$. For alloys, the dendrite tip radius can be expressed as

$$
R \cong\left(\frac{\Gamma D}{-m C_{0} p \sigma^{*} V}\right)^{1 / 2}
$$


where $\sigma^{*}=1 /\left(4 \pi^{2}\right)$, and $\Gamma$ is the Gibbs-Thomson coefficient. Substituting eq. (11) into (10) leads to

$$
\Delta T_{\mathrm{C}} \cong\left(\frac{-m C_{0} p \Gamma V}{\sigma^{*} D}\right)^{\frac{1}{2}} .
$$

The dendrite tip temperatures of $\gamma$-Fe and $\mathrm{T}_{1}$ phase can thus be expressed as

$$
T_{\mathrm{d}}^{0, i}=T_{1}-\Delta T_{\mathrm{C}}^{0, i}=T_{\mathrm{P}}-m_{i}\left(C_{0}-C_{\mathrm{P}}\right)-\Delta T_{\mathrm{C}}^{0, i},\left(i=\gamma-\mathrm{Fe}, \mathrm{T}_{1}\right) .
$$

At lower velocities, the cellular interface growth temperatures can be described as ${ }^{[1]}$

$$
T_{\mathrm{d} / \mathrm{c}}^{i}=T_{\mathrm{d}}^{0, i}-G_{i} D / V
$$

Using eqs. (12)-(14), the growth interface temperatures for cellular or dendritic $\gamma$-Fe and $\mathrm{T}_{1}$ phases can be calculated.

\section{Microstructure selection map}

As shown in Figure 1, the relation between temperature gradient $G_{\mathrm{T}_{1}}$ and withdrawal velocity $V$ can be fitted by

$$
G_{\mathrm{T}_{1}}=14330 \times V^{-0.075} .
$$

Substituting eq. (15) into (4) and using the physical constants given in Table 1, critical velocities for $T_{1}$ phase transition from plane front to cellular/dendritic growth have been calculated. For

\begin{tabular}{|c|c|c|c|c|c|}
\hline Symbol & Unit & Parameter & $\gamma-\mathrm{Fe}$ & $\mathrm{T}_{1}$ & Ref. \\
\hline$m$ & $\mathrm{~K} / \mathrm{at} \%$ & liquidus slope & -16.5 & -7.7 & {$[1]$} \\
\hline$\Gamma$ & $\mathrm{mK}$ & Gibbs-Thomson coefficient & $2 \times 10^{-7}$ & $1 \times 10^{-6}$ & {$[1]$} \\
\hline$D$ & $\mathrm{~m}^{2} / \mathrm{s}$ & diffusion coefficient of $\mathrm{Nd}$ in liquid & $5 \times 10^{-9}$ & $5 \times 10^{-9}$ & {$[1]$} \\
\hline$k_{0}$ & & distribution coefficient & & 0.784 & eq. (9) \\
\hline$C_{\mathrm{S}}$ & at $\%$ & composition of solid phase & & 11.78 & {$[17]$} \\
\hline$C_{\mathrm{LP}}$ & at $\%$ & composition of $\mathrm{L}$ at $T_{\mathrm{P}}$ & \multicolumn{2}{|c|}{15} & {$[17]$} \\
\hline$T_{\mathrm{P}}$ & $\mathrm{K}$ & peritectic temperature & \multicolumn{2}{|c|}{1453} & {$[17]$} \\
\hline
\end{tabular}
$\mathrm{Nd}_{11.76} \mathrm{Fe}_{82.36} \mathrm{~B}_{5.88}$ and $\mathrm{Nd}_{13.5} \mathrm{Fe}_{79.75} \mathrm{~B}_{6.75}$ alloys, the calculated values are $7.0 \times 10^{-6} \mathrm{~m} / \mathrm{s}$ and $1.4 \times$ $10^{-5} \mathrm{~m} / \mathrm{s}$, respectively.

Table 1 Physical constants of Nd-Fe-B

The $G / V_{\mathrm{C}}^{\mathrm{T}_{1}}$ values for various Nd contents of a constant ratio of $\mathrm{Nd} / \mathrm{B}=2$ were calculated using eq. (4), as shown in Figure 9(a). It can be seen that the experimental data match well with the calculated values.

Although the kinetic undercooling may not affect the value of $V_{\mathrm{C}}^{\mathrm{T}_{1}}$, it has effects on the competition between different crystal faces of $\mathrm{T}_{1}$ phase at velocities $V<V_{\mathrm{C}}^{\mathrm{T}_{1}}$, so that in directional solidification experiments, $T_{1}$ phase exhibited a plane front or faceted plane front morphology at low rates.

Figure 10 shows the calculated interface response functions for $\mathrm{Nd}_{11.76} \mathrm{Fe}_{82.36} \mathrm{~B}_{5.88}$ and $\mathrm{Nd}_{13.5} \mathrm{Fe}_{79.75} \mathrm{~B}_{6.75}$ alloys. The calculated $V_{\text {tr }}$ for the two alloys are $3.2 \times 10^{-3} \mathrm{~m} / \mathrm{s}$ and $5.9 \times 10^{-3} \mathrm{~m} / \mathrm{s}$, respectively. At growth rates $V<V_{\mathrm{tr}}, \gamma$-Fe would grow as the primary phase; at $V>V_{\mathrm{tr}}, \mathrm{T}_{1}$ faceted dendrites would become the leading morphology. 


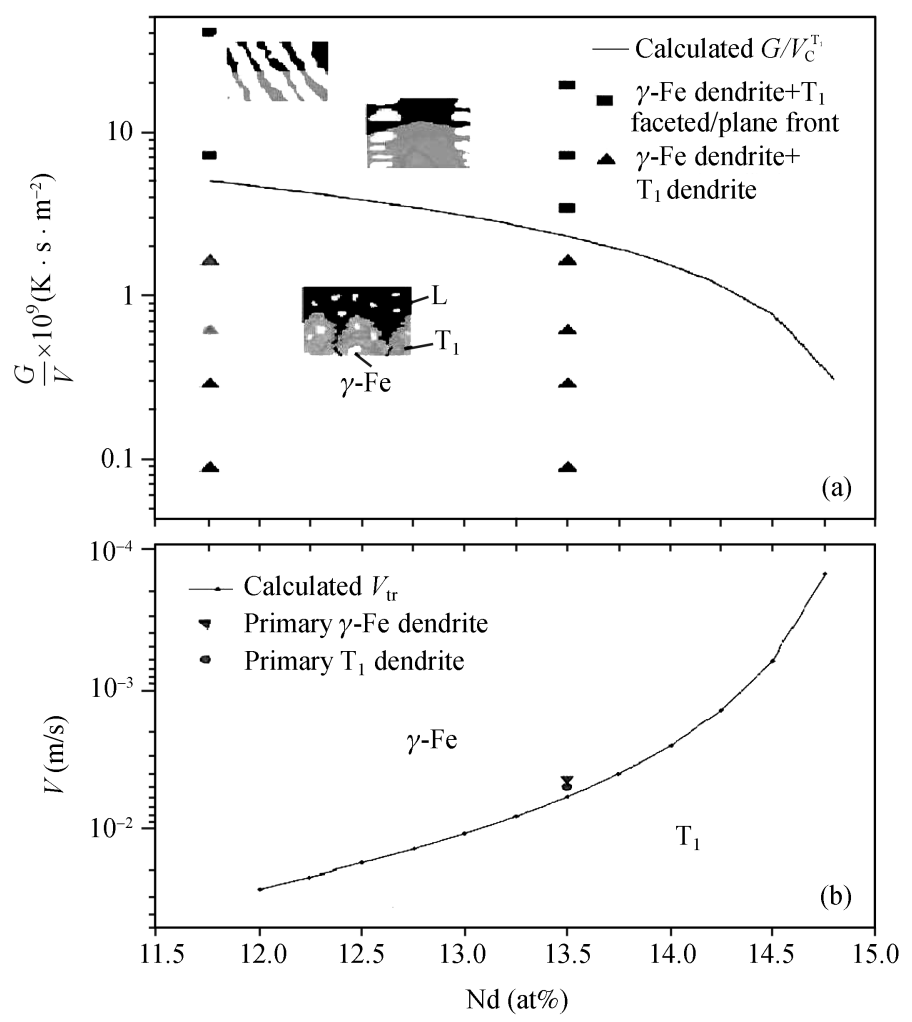

Figure 9 Solidification microstructure selection map of Nd-Fe-B.
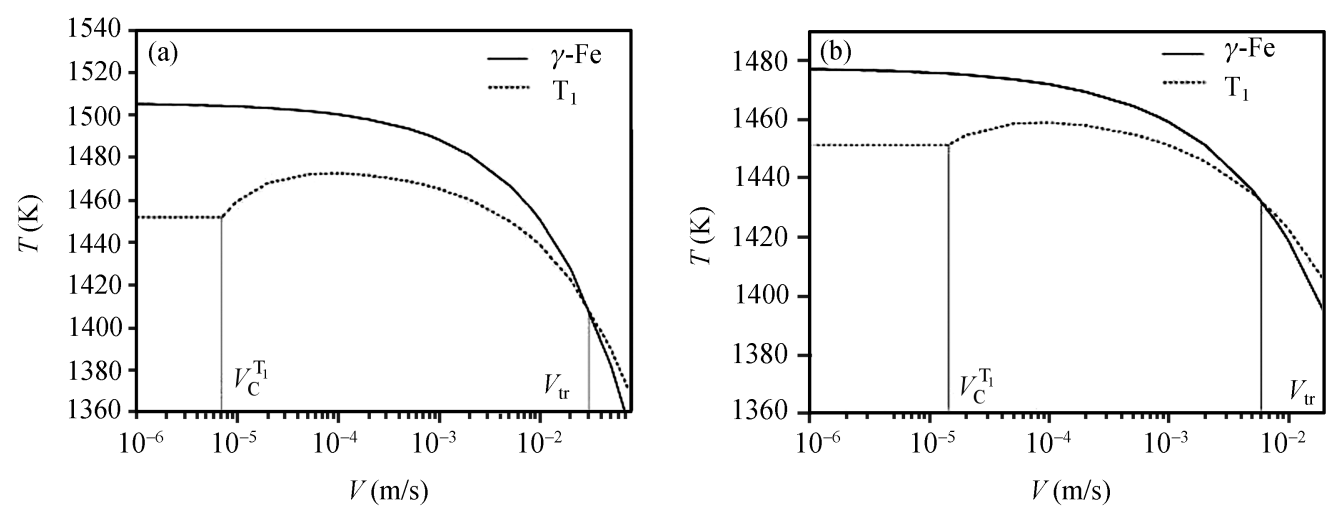

Figure 10 Interface temperatures of $\gamma$-Fe and $\mathrm{T}_{1}$ phases in $\mathrm{Nd}-\mathrm{Fe}-\mathrm{B}$ at different growth rates. (a) $\mathrm{Nd}_{11.76} \mathrm{Fe}_{82.36} \mathrm{~B}_{5.88} ;($ b) $\mathrm{Nd}_{13.5} \mathrm{Fe}_{79.75} \mathrm{~B}_{6.75}$.

Critical velocities for the phase transition from $\gamma$-Fe dendrites to $\mathrm{T}_{1}$ dendrites with different $\mathrm{Nd}$ contents are shown in Figure 9(b). The predicted values of $V_{\text {tr }}$ are higher than that reported by Umeda et al. ${ }^{[1]}$ (For $\mathrm{Nd}_{13.5} \mathrm{Fe}_{79.75} \mathrm{~B}_{6.75}$ alloy, the value of $V_{\text {tr }}$ in their paper is about $1 \times 10^{-3} \mathrm{~m} / \mathrm{s}$, which is about one sixth of the value in this paper). From the laser surface remelting experiments, the value of $V_{\text {tr }}$ for $\mathrm{Nd}_{13.5} \mathrm{Fe}_{79.75} \mathrm{~B}_{6.75}$ alloy was investigated to be in the range between $4.4 \times 10^{-3}$ $\mathrm{m} / \mathrm{s}$ and $5.0 \times 10^{-3} \mathrm{~m} / \mathrm{s}$, which is in approximate agreement with the calculated value, as shown in Figure 9(b).

Figure 9(a) and (b) gives the microstructure selection map of Nd-Fe-B alloys with peritectic and 
hyperperitectic compositions, containing plane front at low velocities and dendritic morphologies at higher velocities.

\section{Conclusions}

(1) Critical velocities $V_{\mathrm{C}}^{\mathrm{T}_{1}}$ for the $\mathrm{T}_{1}$ phase transition from plane front to cellular/dendrite interface have been calculated. The values of $\mathrm{Nd}_{11.76} \mathrm{Fe}_{82.36} \mathrm{~B}_{5.88}$ and $\mathrm{Nd}_{13.5} \mathrm{Fe}_{79.75} \mathrm{~B}_{6.75}($ at $\%)$ alloys are $7.0 \times$ $10^{-6} \mathrm{~m} / \mathrm{s}(G=349 \mathrm{~K} / \mathrm{cm})$ and $1.4 \times 10^{-5} \mathrm{~m} / \mathrm{s}(G=331 \mathrm{~K} / \mathrm{cm})$, respectively. In Bridgman directional solidification experiments, with increasing growth velocities, $\mathrm{T}_{1}$ phase changed from plane front or faceted plane front to faceted dendrites. The experimental results are in good agreement with the calculated values.

(2) Critical velocities $V_{\text {tr }}$ for transition from primary $\gamma$-Fe dendrites to $\mathrm{T}_{1}$ dendrites were calculated. The value of $V_{\text {tr }}$ for $\mathrm{Nd}_{13.5} \mathrm{Fe}_{79.75} \mathrm{~B}_{6.75}\left(\right.$ at $\%$ ) alloy is $5.9 \times 10^{-3} \mathrm{~m} / \mathrm{s}$. During laser remelting experiments, $V_{\text {tr }}$ for $\mathrm{Nd}_{13.5} \mathrm{Fe}_{79.75} \mathrm{~B}_{6.75}$ alloy was investigated to be in the range between $4.4 \times 10^{-3}$ $\mathrm{m} / \mathrm{s}$ and $5.0 \times 10^{-3} \mathrm{~m} / \mathrm{s}$. The experimental result is in reasonable agreement with the calculated value.

(3) A microstructure selection map for Nd-Fe-B alloys was presented using both the criterion of the highest interface temperature and directional solidification experimental results.

1 Umeda T, Okane T, Kurz W. Phase selection during solidification of peritectic alloys. Acta Materialia, 1996, 44: 4209-4216

2 Ozawa S, Saito T, Motegi T. Effects of cooling rate on microstructures and magnetic properties of Nd-Fe-B alloys. J Alloys Compds, 2004, 363: 263-270

3 Ozawa S, Saito T, Yu J, et al. Solidification behavior in undercooled Nd-Fe-B alloys. J Alloys Compds, 2001, 322: $276-280$

4 Huang W D, Lin X, Wang M, et al. Pattern and phase selection of peritectic reaction during directional solidification. Sci China Ser E-Eng Mater Sci, 2002, 45(5): 458-466

5 Xu W, Feng Y P, Li Y, et al. Rapid solidification behavior of Zn-rich Zn-Ag peritectic alloys. Acta Materialia, 2002, 50: $183-193$

6 Trivedi R, Park J S. Dynamics of microstructure formation in the two-phase region of peritectic systems. J Cryst Growth, 2002, 235: $572-588$

7 Lo T S, Dobler S, Plapp M, et al. Two-phase microstructure selection in peritectic solidification: From island banding to coupled growth. Acta Materialia, 2003, 51: 599-611

8 Lograsso T A, Fuh B C, Trivedi R. Phase selection during directional solidification of peritectic alloys. Metall Mater Trans, 2005, 36: $1287-1300$

$9 \mathrm{Su}$ Y Q, Liu C, Li X Z, et al. Microstructure selection during the directionally peritectic solidification of Ti-Al binary system. Intermetallics, 2005, 13: 267-274

$10 \mathrm{Ma} \mathrm{D}, \mathrm{Li} \mathrm{Y}, \mathrm{Ng} \mathrm{S} \mathrm{C}$, et al. Unidirectional solidification of Zn-rich Zn-Cu peritectic alloys (I): Microstructure selection. Acta Materialia, 2000, 48: 419-431

$11 \mathrm{He}$ Q, Liu L, Zou G R, et al. Investigation of microstructure of Nd-Fe-B peritectic alloys under directional solidification. J Mater Eng, 2004, 6: 17-19

12 Su Y P, Lin X, Wang M, et al. Lamellar structures in laser surface remelted $\mathrm{Zn}$-Cu peritectic alloy under ultra-high temperature gradient. Scripta Materialia, 2004, 51: 397-403

13 Kurz W. Solidification microstructure processing maps: Theory and application. Adv Eng Mater, 2001, 7: 443-452

14 Matsuura Y, Hirosawa S, Yamamoto H, et al. Phase diagram of the NdFeB ternary system. Jpn J Appl Phys, 1985, 24: 635-638

15 Li J F, Zhou Y H. Effect of interface kinetics on the eutectic growth. Sci China Ser E-Eng Mater Sci, 2005, 48(4): 361-371

16 Kurz W, Fisher D J. Fundamentals of Solidification. 4th ed. Switzerland: Trans Tech Publications Ltd., 1998. 54-240

17 Zhou S Z, Dong Q F. Super Permanent Magnet-Rare Earth Iron Series Permanent Magnet Material. 2nd ed. Beijing: Metallurgical Industry Press, 2004. 84-91 